\author{
Military Technical College \\ Kobry Elkobbah, Cairo, \\ Egypt.
}

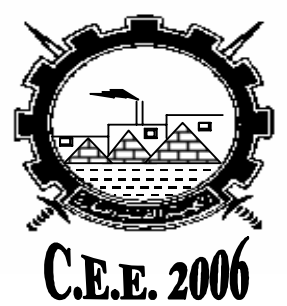

$3^{\text {rd }}$ International Conference

On

Chemical \& Environmental

Engineering

\title{
FEASIBILITY OF FLOTATION TECHNIQUES FOR TREATMENT OF AQUEOUS EFFLUENTS OF THE EDIBLE-OIL INDUSTRIES
}

\author{
Abdel Wahhab M. Z. * and Ashour E. A.**
}

\begin{abstract}
The Edible-Oil industries in Egypt consume about $6000 \mathrm{~m}^{3} / \mathrm{h}$ of water. Effluents from these industries accompany more than 6000 tons per year of edible oils, which are actually lost due, either to lack of efficient treatments, or due to the in-efficiency of these treatments. Many methods had been used for treatment of effluents, the physical methods of which proved to be the best. The use of flotation as a technique for treatment of such effluents is restricted by some special requirements for such a technique. Many researches, thus, were done to overcome such restrictions, yet they had not arrived to solution which could be considered as to be vital as a solution. This research is, thus, a trial of new mode, with a clear objective to discover a possibility of recycling the oil contaminated with the aqueous effluents from the edible-oil industries, on a laboratory scale, as a step on a train of trials which will follow. Results revealed the success of the first step to reach nearly complete re-gain of the lost oil with those effluents, by the use a new mode of distributors which was not common in use for such techniques and by some modifications of the treatment processings steps by the flotation technique.
\end{abstract}

\section{KEY WORDS}

Recycling-Pollution control-Flotation -Aqueous effluents- Edible oil Residues .

\footnotetext{
* Faculty. Of Engineering., El-Minia University.
} 


\section{1- INOTRODUCTION}

More than six hundred tons of edible oils are annually lost from the edible-oil industries in Egypt, accompanied by about six hundred cubic meters of water effluents from these industries. This is either due to lack of treatment of the aqueous effluents of these industries, or, due to the in-efficiency of those treatments. Usual treatments for aqueous effluents include methods such as : filtration (packed bed, activated carbon or membrane filtrations) [1-3], hydrocyclones [4], and flotation (gas, induced gas , and dissolved gas flotations) [5-12]. These are the physicochemical treatments, which are, in most cases, preferable than other biological or electro chemical methods. In most cases, filtration and hydrocyclones are in common use due to their ease of fabrications, installations, and in maintenance . Yet, the use of flotation is restricted to its special requirements of the treatment processing, in spite of its huge merits in processing steps, yield, ease of manipulation and treatments, and in its low capital costs. Gas flotation is an accelerated gravitational technique in which fine gas bubbles are injected into a water phase containing immiscible drops of another phase or solid particles, where the gas bubbles attach themselves to these droplets, becoming then lower in density and thus be able to float. This action is governed by the stokes law and is thus controlled by the same factors affecting the floatability of such droplets, such as : the hydrodynamic forces (movement of bubbles, drops and continuous phase ), the thermodynamic forces ( interfacial interactions ), and by the physico-chemical interactions. The efficiency of separation can be increased by coalescence of oil drops by the use of some surface active agents, and / or , chemical demulsifiers.

Dissolved air flotation (DAF), and induced air flotation (IAF), are two well known techniques for gas flotation, each of which, has its own factors affecting the overall efficiency of the flotation process. The points to be considered in comparison and choice must consider the method of bubble generation, the contact between gas bubbles and oil droplets, the attachment of the oil drops to the gas bubbles, the characteristics of rising of the air/oil combinations (clusters) and the type of the flotation column itself and its design features.

Many researches are in hand considering the conditions of laboratory gas flotation [13-15] and the conditions and techniques which can be followed [16-19]. Nozzle flotation (NF) , column flotation, centrifugal flotation (CF) and cavitations flotation $(\mathrm{CAF})$, are some of the normally used techniques on a laboratory scale [20-24]. On an industrial scale, these techniques are, to some extent, a matter of question due to some troubles always arising on a daily scale. In spite of such troubles, the flotation technique has been used successfully in concentration of bacteria, algae and some other micro-organisms [25,26]. Proteins [27], plastics [28], paper deinking [29] and removal of fatty acids and residues [30-32] , are some other useful applications with acceptable efficiency on a large scale.

The objective of the present investigation is to study the possibility of using flotation techniques for recycling the oil contaminated with those aqueous effluents from the edible -oil industry so as to minimize losses and maximize oil yield, and thus, the industrial profitability. This step of study is done on a laboratory scale using batchwise conditions hoping to be followed by semi-pilot, pilot and a large scale application steps. An economic evaluation study will be the last step in that train of trials which necessitates a comparison with the nowadays used methods. 


\section{2- MATERIALS}

\section{(a) Aqueous Oily Effluent}

Is a real industrial sample of an oil/water suspension effluent from the Tanta Oil and Soap company, Tanta, Egypt. The following is the chemical analysis of that sample ; the $\mathrm{pH}$ for which is found to be 8.3 , and thus conforming with the maximum permissible range for drainage of effluents (6-9 $\mathrm{pH})[21]$ :-

$\begin{array}{llllll}\text { Oil and grease } & 450 & \mathrm{ppm} & \text { Phosphates } & 2 & \mathrm{ppm} \\ \text { Dissolved solids } & 1400 & \mathrm{ppm} & \text { Nitrites } & 10 \mathrm{ppm} \\ \text { Suspended solids } & 40 & \mathrm{ppm} & \text { Florides } & 0.05 \mathrm{ppm} \\ \text { Sulfides } & 0.04 & \mathrm{ppm} & \text { Phenols } & 0.001 \mathrm{ppm} \\ \text { Heavy metals } & 0.01 & \mathrm{ppm} & \text { Cyanides } & \text { nil }\end{array}$

The sample is thus within the range of permissible limits for draining effluents in seas [21], except for its content of oils and greases which has a limitation of $10 \mathrm{ppm}$ only [21] .

\section{(b) Chemicals}

\section{Surface Active Agents}

This has the trade name "SAVO"; which is an ionic sulphonyl based emulsifier used in the solid state, from which a $1 \%$ solution was prepared.

This agent assists in reducing the surface tension, increasing the wettability of the test sample solution and the stability of the colloidal oily system under test.

\section{Foaming Agents}

This is a prepared soap solution , $0.5 \%$ concentration, of the soda type, so as to create a froth, mainly sodium naphthenes .

\section{Softening Agents}

A soda ash solution ( $1 \%$ ) was prepared and used to ensure the absence of calcium and magnesium salts which may interfer with the flotation efficiency [21].

\section{Alkalies and Acids}

A two percent sodium hydroxide solution and a diluted solution of a concentrated nitric acid base are used to adjust the $\mathrm{pH}$ of the test solution to the required testing value. These chemicals were prepared from A.R. chemicals.

\section{3- APPARATUS}

This is a Perspex column , $10 \mathrm{~cm}$ diameter and $120 \mathrm{~cm}$ length, vertically installed in position (Fig.1 ). The column contains side sampling openings at $10 \mathrm{~cm}$ spacings, arranged to cover two-thirds of the column length at least. The floating foam resulting from the flotation process can be collected through an arrangement fitted around the top of the column. The column bottom is a $10 \mathrm{~mm}$ thick Perspex plate which can be mantled and dismantled. Three designs of that plate are prepared for testing, one is perforated allover the area of the working plate diameter, such that U-tube bends of one millimeter internal diameter can be fixed in each one of these perforations 
forming an inverted outlet directed towards the plate remaining solid area. Another design of that plate is a one-hole plate in which one bubble-cap is fitted. This bubblecap contains 80, one millimeter holes in its lower surface, as shown in Fig.1. A third experimented plate is an ordinary one-sparger plate having a central nozzle of about $5 \mathrm{~mm}$ diameter.

The lower part of the column is an upright cone acting as a chamber for collecting the air injected through the plate spargers to effect charge flotation requirements. An air compressor (one stage ) is used for air injection inside the column through the collecting chamber, up to the plate spargers or bubble-cap. A flow meter is used for measuring the air flow rate. An Lp 2000 microprocessor-based, bench turbidity meter is used for following changes in the dispersed oil concentration allover the column height. The column operation through out the present work is of the barchwise type arrangement.

\section{4- METHODS}

\section{a - Preparation of the Test Sample}

The volume required to fill a volume of the set-up column, up to a certain height, is determined experimentally by preliminary trials. To extract such a volume from the whole stock, this is thoroughly mixed by a mechanical stirrer for half an hour to ensure homogeneity, and the required volume is transferred, using a centrifugal pump, to a preparation vessel. The required detergents and foaming agents are added while mechanically mixing the sample in the preparation vessel at a slow rate of mixing to prevent foam formation. The $\mathrm{pH}$ is adjusted for the charge using the prepared alkali or acid. The amounts and specifications of these chemicals added were determined experimentally by trials so as to have the best conditions of flotation stability of the charge; these findings were fixed allover the experimental procedure , except whenever other wise mentioned in the present text.

\section{b- Emulsion Stability Conditions}

Ten samples of the homogeneous stock were put in separate containers, additives (emulsifier, surface active agent, softening agent and foaming agent ) were added as specified for each sample. The samples were then mixed well for half an hour at a moderate rate of mixing (600-800 rpm ), and left overnight. Turbidity of 3-levels (bottom, middle and near surface) for each sample is determined. The amounts of emulsifier, surface active agent, softening agent and foaming agent required to give a uniform turbidity measuring values (within \pm 10 FTU) were that determined whenever it was found that the 3-level measurements for a sample are approching each others.

Experiments were thus designed to use these additives within the range determined for these chemicals to obtain a stabilized emulsion. Emulsifying agent was found to give stability if being in the range of $500-800$ ppm; other chemicals were found to affect stability with nearly constant amounts; the minimum amount of these chemicals which affect stability, were used.

\section{c -Turbidity Measurements}

This was done by a LP 2000 turbidity meter which is microprocessor-based, with an accuracy ( at $20^{\circ} \mathrm{C}$ ) of $\pm 5 \%$. The ranges of measurement of such a meter is up to 50 FTU and up to 1000 FTU for two different techniques of processing. A formazine 
turbidity unit (FTU) is equal to a nephelometric turbidity unit (NTU ). The light source of the turbidity meter used is a high emission infrared LED with a wave length peaking at $890 \mathrm{~nm}$, which reduces interferences caused by coloured samples to a minimum. A sensor, positioned at $90^{\circ}$ angle with respect to the direction of light detects the amount of light scattered by the undissolved particles or drops in the sample. The microprocessor converts such readings into FTU values. Before use, this instrument was tested for accuracy by the use of supplied standard solutions , one at zero FTU values and the other having 10 FTU readings. Following the instructions given in its manual, the instrument gives highly accurate readings for suspensions having FTU values lower than 40; if higher readings are to be detected, dilutions are best made before measurement. Calculations are made, then , to have the correct FTU for the samples, using the calibration solutions (suspensions ) given with the instrument. For example, if the total volume is $(100 \mathrm{ml})$, and the original volume of the sample is (VOS $\mathrm{ml}$ ), then VOS $=300 / \mathrm{T}$, where $\mathrm{T}$ is the instrument reading exceeding 40 FTU [35]. The correct turbidity value of the original sample is then given by [35]:

$\mathrm{Ta}=\operatorname{Tn}(100 / \mathrm{VOS})$,

where $:$ Ta $=$ actual turbidity value of the original sample

$\mathrm{Tn}=$ instrument reading of the diluted solution

Vos = A notation for "volume of Sample "

\section{d- Calibration Curves for Turbidity Measurements}

Since the LP 2000 turbidity instrument has a maximum sensitivity for samples of FTU readings up to $40 \mathrm{FTU}$, two calibration curves were made ; one for samples readings up to $40 \mathrm{FTU}$ and the other for samples readings exceeding this value . Both curves were made by preparing samples of different oil contents by dilutions from the original real sample ( of $450 \mathrm{ppm}$ oil content ). These samples were made by using ordinary tap water for dilutions. The curves obtained were nearly of straight lines with some curvatures, put it was found better to read correct values from the curves without approximations (Fig.2).

\section{5- PROCEDURE}

To begin an experiment, the set-up is put in position (Fig.1), and different items are connected, cleaned and tested. The required type of plate selected is put in place within the set-up. Air is admitted at a slow rate and the prepared amount of oily water is directed to fill the required volume of the column. The pre-planned air flow rate and time of flotation are taken into consideration before ending that experiment. Samples are taken at different levels at prescribed time plan for each experiment.

To end an experiment, the oily water contained in the column is evacuated, compressor is put-off and all items are dismanteled, cleaned and re-put in position within the set-up and connected together, awaiting for a following testing experiment .

\section{6- RESULTS AND DISCUSSIONS}

Some important factors affecting the flotation process were chosen, neglecting some others which could not be tested due to some restrictions; the chosen factors are : air flow rate; initial oil concentration, time of flotation, working height of the oily water 
in the column and finally the design of the air distributing plate in the bottom of the column. The batch operation was chosen to be the first step of study, which is to be followed by testing the continuous operations on a laboratory scale. A comparison between the tested plates efficiencies and the efficiency of the ordinary used onesparger plate is also done.

\section{a- Effect of Air Flow Rate}

Four air flow rates were tested; these are: 800, 1200, 1600 and $2000 \mathrm{ml} / \mathrm{min}$. Only samples at mid-height of the original oily water level are considered for comparison. Figure 3 represents the results obtained. It is clear that largest air flow rate gave the best oil gain ( \% removal). This flow rate shows also the highest percentage gain at the least time of flotation ( about 5 minutes ). Figure 3 shows also that a total flotation time of 20 minutes is sufficient to gain nearly all the oil content of the charge. These observations comply with theoretical basics, since higher flow rates mean higher amount of bubbles for a certain time which allow for higher carry-over of the oil content of the charge. It is to be noted here that trials to increase low rates of air than $2000 \mathrm{ml} / \mathrm{min}$ gave lower removal efficiencies due to high turbulance of the charge which breaks the rising bubbles, resulting in a decrease in the percentage removal of oil (i.e. decrease in the oil gain percentage ). To study other factors affecting the oil gain process an intermediate flow rate of $1600 \mathrm{ml} / \mathrm{min}$ was used so as to have clear comparative values of oil gain.

\section{b- Effect of Initial Oil Concentration of The Charge}

Perhaps, it was not so important to study such an effect with respect to the present investigation, since the actual original concentration of oil in the obtained effluent is well identified and could not be changed. It is thus just an additional study in order to be ready for any occasional changes in the oil content during daily operations in industry, which is almost a fact. It is thus well understood that the maximum oil concentration to be used is that of the sample in hand, obtained from industry . By dilutions, thus, other concentrations may be prepared. The studied initial concentrations $\left(C_{\circ}\right)$ were : 50, 150, 250,350 and 450 ppm samples.

Figure 4 is an illustration for the results obtained. It can be observed that initial concentration $\left(\mathrm{C}_{\mathrm{o}}\right)$ affects the oil gain; increasing oil concentration in the tested charge increased the final gain of oil for a certain time of flotation. Yet, after a certain oil concentration of the original charge (250 ppm in the figure ) the original concentration has nearly no effect. Thus, it is advisable for dilute oil contents of the effluents, that the time of flotation is to be increased so as to attain acceptable oil gain. At a certain air flow rate, the number of bubbles as well as their size and hydrodynamics remain the same. In dilute solutions and for a certain fixed time of flotation, air bubbles will be in abundance and can carry over oil particles which increase in number by increasing the initial concentration of the charge. At a certain limit of oil concentrations, thus, it is expected that the rate of bubble formation will be less than what is required for the carryover of all oil particles and thus a nearly constant gain of oil will be noticed for any further increase in oil in the charge. The need is, thus, to increase the flow rate of air and / or the time of flotation. 


\section{c- Effect of Flotation Duration}

Examining more Fig.3. shows that the increase of time of flotation increases the oil gain at all rates of air flow. This can be easily attributed to the additional chances given to the charge to be depleted from its oil content by the continuous flowing rate of air stream. New bubbles of air flow will carry more and more oil by time increase. It is also expected that the rate of oil carryover may increase by time since new bubbles will affect, to a large extent, the remaining amount of oil in the charge having a decreased oil content by elongation of the flotation period.

\section{d-Effect of The Working Height of The Column Charge}

As previously mentioned, the height of the column charge used in all experimental tests was $80 \mathrm{~cm}$, which fills two-thirds of the column height $(120 \mathrm{~cm})$. This gave no troubles in operation of the column and its efficiency in oil gain. It was suggested to study other charge heights in the column, just for comparison and to ensure whether the chosen height $(80 \mathrm{~cm})$ was the best.

Figure 5 represents the results obtained. It was decided to decrease the air flow rate used in studying this factor in order to decrease the final oil gain as shown by figure 3 , and thus to enlarge the difference in oil gain by changing charge height in the column.

Figure 5 shows that the oil gain increases by increasing charge height in the column up to a certain limit (about $50 \mathrm{~cm}$ height ), remaining after that nearly unchanging to about $70 \mathrm{~cm}$ height charges, then decreasing. The figure shows also that the chosen height for all tests $(80 \mathrm{~cm})$ was not the best; yet it is clear that it is not the worst .

The effect of the charge height in the column may be attributed to the stability conditions of the rising bubbles which are highly affected by the time of bubble rising through the charge, the rate of their rising, the bubble size and by the diameter of the column which may interfere by the wall effects for narrow columns on the stability of bubbles. Also one can not neglect the effect of bubble collisions in between of them and with the walls of the column allover the height of the charge till a bubble can reach the charge surface.

\section{e-Effect of Air Inlet Conditions}

Air inlet conditions to the flotation column is governed by some operating factors and other design factors. Air pressure, air flow rate, air quality as well as the charge height in the column are operating factors which can be chosen for each experimental procedure. On the other hand, some designfactors such as the column diameter, material of construction, column height and the distributor design for air inlet are to be taken into consideration before manufacturing and erecting the column itself. Of these design factors, the plate ( distributor ) design is of great importance . The following are data given to ensure this importance from a practical point of view on a laboratory scale.

Figure 7 presents the percentage oil gain for each design having all other factors, whether operating or design, the same ; the air flow rate was chosen to be 1200 $\mathrm{ml} / \mathrm{min}$ for reasons previously presented in item (4) of that section.

Examination of the results in Fig.7 shows an advantage for the design $(A)$ of the distributor plate. The design (B) is no longer acceptable, while the design (C), which 
is commonly used in flotation columns, is the least efficient of them. Yet, all of them reached to nearly complete oil gain within about 25 minutes. The reasoning is quite clear, that the bubble cap design gives higher pressure of impact with the bottom plate of the column and thus higher number of air bubbles, perhaps more than the (B) design whose effect is quite approaching that of design (A). In design (B) the exit pressure from the tip of each inverted pipe is expected to be of lower even distribution and of lower pressure of impact than the air exit from the evenly distributed holes of the bubble cap. The number of bubbles will be consecutively higher and hydrodynamics will be much more effective for oil coalescence and contact with bubbles, perhaps also the time for coalescence is expected to be much more less for the bubble cap design than the inverted pipes design. This difference in mechanisms is expected also to be more effective for continuous operations of that flotation process, such an expectation is a matter of question awaiting for the results to be obtained in the second planned phase of that research .

\section{7- CONCLUSIONS AND RECOMMENDATIONS}

The present investigation, done on a real sample of an aqueous industrial effluent revealed an expected efficient use of flotation techniques in recycling edible oils from the aqueous effluents of these industries to gain about 6000 ton per year of edible oils. On a laboratory scales flotation efficiency approaches complete oil gain . Some design and operating factors were studied to prove the feasibility of flotation techniques for oil gain, the most important of which is found to be the plate (distributor ) design of the column bottom, some ideas used in unit operations other than flotation is found to be effective in flotation techniques which the buble cap design, normally used in distillation and absorption plate columns. This new field of application may be of higher importance for continuous laboratory and field applications. The time of oil gain is found to much lower than other common processes and for lower air flow rates the efficiency and yield in flotation technique is found to be 19-24 percent more then common other techniques. Research continuation for a continuous operation will removal and prove such fact obtained on a batch operation procedure.

It is recommended, thus, to extend these trials to be on a semi-pilot scale, if continuous operations on a laboratory scale confirm batch data obtained. It is also of importance to enlarge the scope of design factors affecting the process so as to study, qualitatively and quantitatively, the scaling-up procedures for industrial applications. It is clear that an economic evaluation is to be finally done to give clear and wise budget information to the industrial side responsible for application.

\section{ACKNOWLEDGEMENT}

The authors appreciate well the effort done by collegues, assistants and technicians in El-Mansoura and Tanta Universities for collaboration and discussion of a large part of that research. 


\section{REFERENCES}

[1] Kamal, T. and Youssef, M., " Recovery of Oil residues from oil and Soap industry " , Sump of " Recovery and Recycling of industrial wastes , pp 63-82, Cairo , April (1987).

[2] Beacon, D.K."and filtration cuts pollutions",Oil and gas J.,pp.32-37,June (1973).

[3] Urea, T., "Effect of pore size distribution of ultra filtration membranes ", Water Science and Technology, pp 42-47,(1955).

[4] Editor, " Separating Oil from Water " , The chemical engineer , V 494, (11), pp. 19-28 , April (1991).

[5] Arnold, K.E., "Design concepts for offshore produced water treating and disposal system", J. particle Techn., pp 276-283 , Feb. (1983 ).

[6] Strickland, W.T., " Lab. Results of cleaning water by gas flotation " , Soc. Pet. Eng. J., 10, pp 175-190 (1980).

[7] Arnold, K.E. and Stewart, M., " Surface production Operations " , Gulf Publ. Co., Houston, Texas (1998).

[8] Moosai, R. and Dawe, R.A., " Oily Waste water Clean up by gas flotation " , West Indian J. Eng., 25 (1), pp 25-41 (2002).

[9] Kitchner, J.A., "The froth flotation process : Past, Piesent and Future " , NATO ASI Series no.75, pp 3-51 (1984).

[10] Jamson, G.J., " Physics and hydrodynamics of bubbles ", NATO ASI Series no. 75, pp. 53-77 (1984).

[11] Finborud, A., Faucher , M. and Sell man , E., " New method for improving oil droplet growth", SPE Annual Techn.Conference, Houston, Texas, Oct. (1999).

[12] Vander Zande, M.J., Janssen, P.H> and Van der Broek, W.M.G.T., " Size of oil droplets under high water-cut condition ", SPE production and Operations Symposium, Oklahoma, March (2001).

[13] Sylvester , N.D. and Byeseda , J.J., " Oil-Water Separation by induced air flotation " , Pet. Eng. J., 10, pp. 579-590 , (1980 ).

[14] Moosai, R. and Dawe, R.A.," "Gas attachment of oil droplets ", Separation and Purification Technol., V33, No.3, pp. 303-314, Nov. (2003).

[15] Angelidou, C., Keshavarz, E., Richardson, M.J. and Jamson, G.j., "Removal of emulsified oil particles from water" , Ind. Eng. Chem. Process , Des., Dev., V16 , No.3 (1977) .

[16] Van Ham, N.J.M., Behile , L.A. and Svrcek , W.Y., " The effect of air distribution on flotation of fine oil in water emulsions " , can. J.Chem.Eng., V61, pp. 514547, Aug. (1983).

[17] Pal , R. and Masliyan, J., " Oil recovery from Oil-Water emulsions" , Can. J. Chem. Eng, V68 , No.6 , pp. 959-967, Dec. (1990).

[18] Garovinkov, M.D., Zivanov, V., Karlovic, Z.F.and Clja, D.B., " Recovery of oil from refinery waste water " , can. J. Chem.Eng, V 68, No.6, pp. 969-990(1990 ).

[19] Sylvester, N.D. and Byeseda , J.J. " Oil- Water Separation", U.S.A. Tulsa Natco Soc. Of Petr. Eng. Of AIME, Dec. (1980).

[20] Stricle , W.T., and "Lab. results of cleaning water by gas flotation " , SPE-shell Dev. Co., Soc. Of petr. Eng. , June (1980).

[21] Bennett, G.F., " Removal of Oil from wastewater ", Critical Review in Environmental control, V 18, No. 3, pp. 189-253 (1988). 
[22] Gopalratnam , C., Bennett, G.F. and Peters , R.W., "Removal of Oil and heavy metals from industrial wastewater", Environmental Progress , 7, pp. 84-92 (1988).

[23] Jordan , C.E. and Susko, F.J., " Rapid flotation using bubble-injected hydro cyclone " , Minerals Engineering, 5, pp. 1239-1245 (1992) .

[24] Colic, M., Morse , D.E., Morse, W.O., Motherly, T.G., and Miller , J.D., "From air - Sparged hydrocyclone to bubble accelerated flotation " , proceedings of 4 th DAF, pp. 301-318 (2001).

[25] Jamson, G.J. and Manlapig, E.V., " Applications of the Jamson flotation cell" , Hyma editions, column 91, V2, pp 675-687 (1991).

[26] Smith, R.W., " Liquid and Solid Wastes from mineral processing plants " , Min. Proc. And Extrac. Met. Review , 16, pp.1-22 (1996).

[27] Jamson , Y.Y. G., "Application of the Jamson cell technology for Algae and phosphorus removal", proceedings of 4 th DAF., Tahoe City, V2, pp. 650-671 (2001).

[28] Schneider , I.A.H. , Smith, R.W. and Rubio, J., " Separation of Soybeam protein by DAF " J. Resource Environ. Biotech., 1, pp 47-64 (1995).

[29] Shibata, J., Matsumoto, S., Yamamoto, H.,Kusaka, E., Pradip, M., " Flotation Separation of plastics ", Intern. J. mineral Processing , 48, pp. 127-134 (1996).

[30] Finch, A. and Hardie, C.A., " Innovation from the waste management industry " , Minerals Engineering , 12, (5) , pp. 467-475 (1999).

[31] Ososkov, V., Kebbekus, B., "Removal of organic material using flotation " , Project, New Jersey Institute of Techn., (1997).

[32] Egyptian Irrigation Ministry Report , " Specification of Ind. Waste water drained to seas " , (1982).

[33] Manual, HANNA Instruments , LP 2000 manual, ISO 9000 certified (1992). 


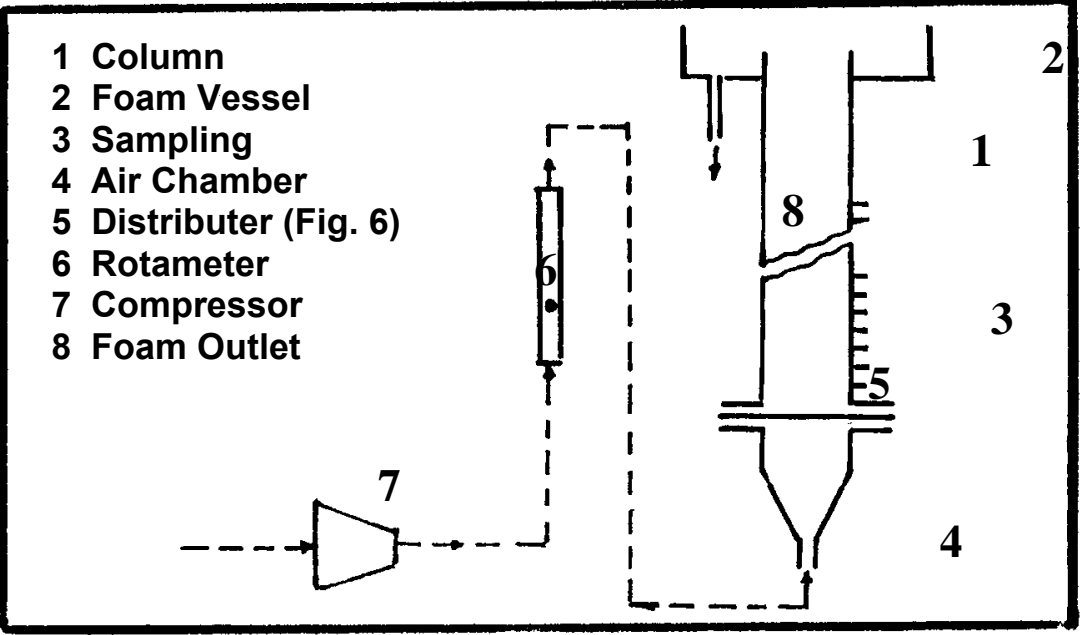

Fig. 1. The Set-up connections

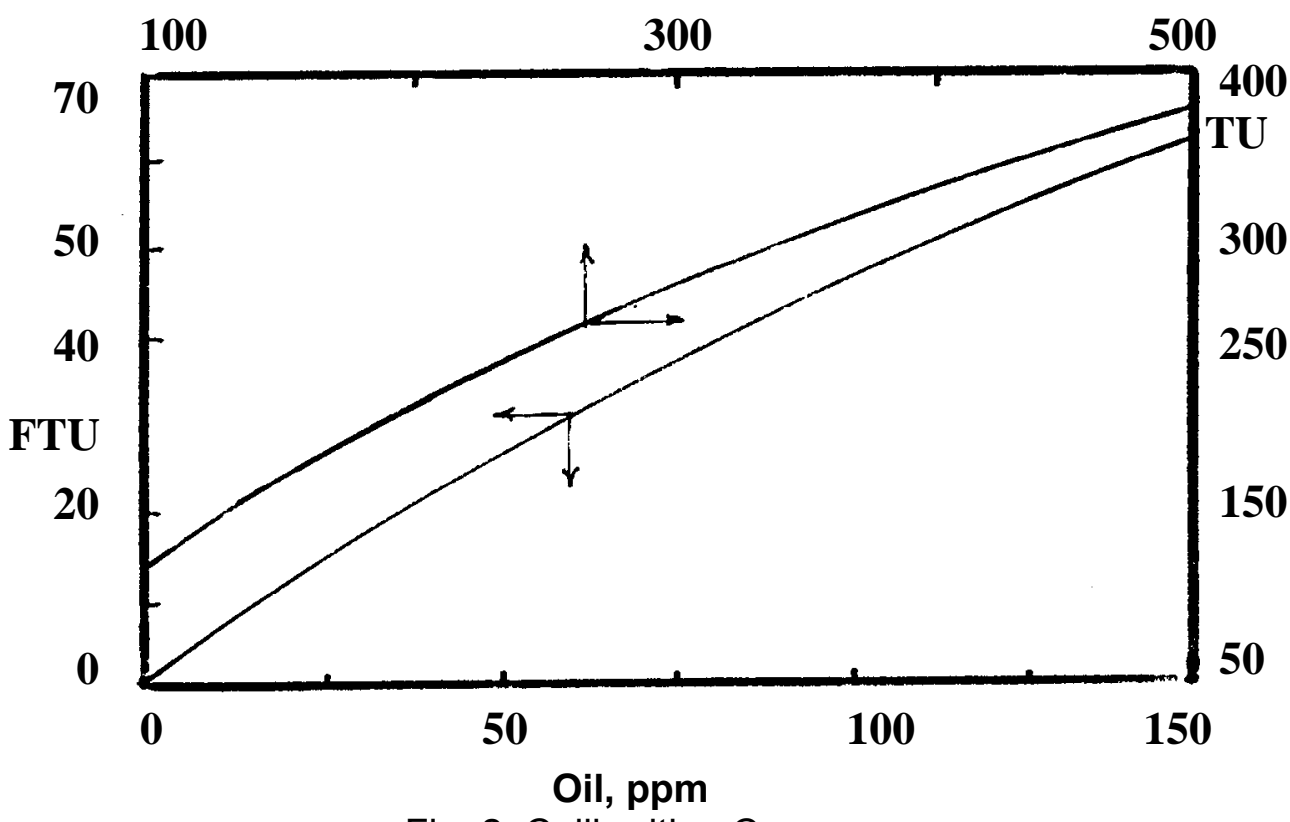

Fig. 2. Calibraltion Curves



Fig. 3. Effect of Air Flow Rate 


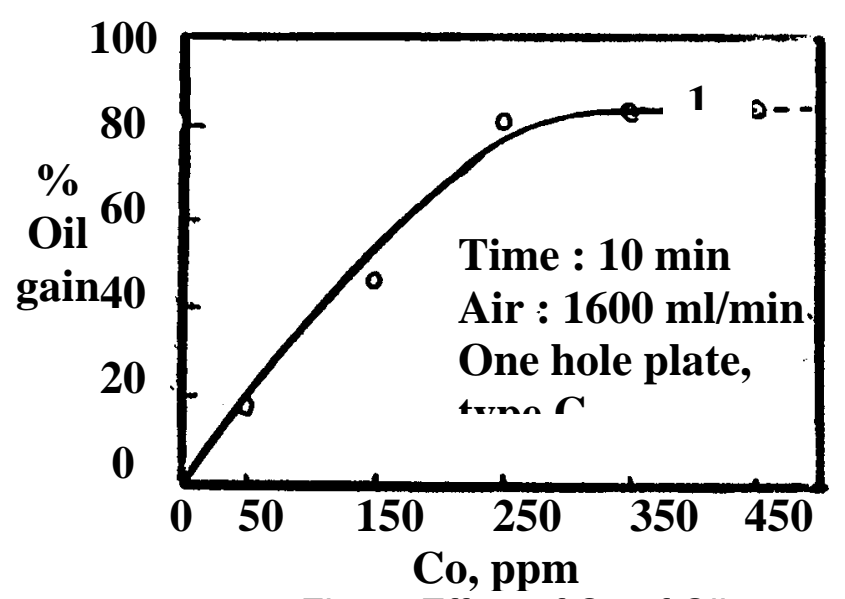

Fig. 4. Effect of Co of Oil

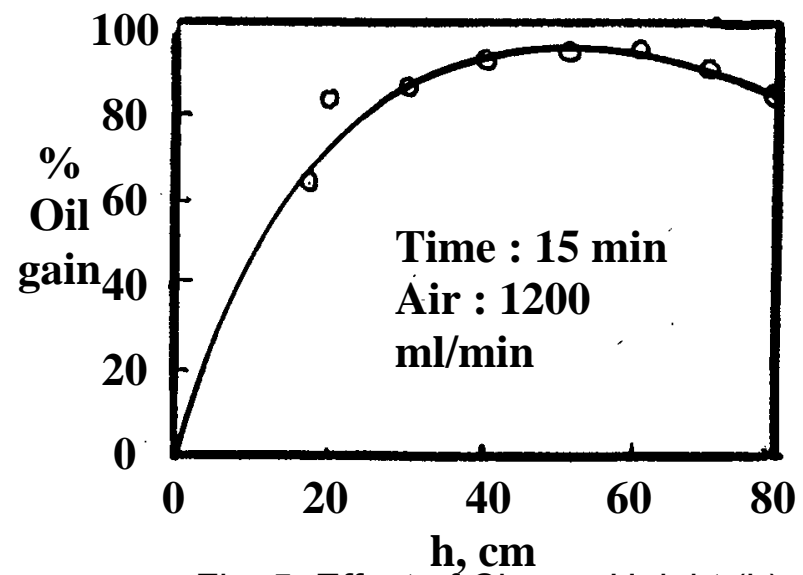

Fig. 5. Effect of Charge Height (h)
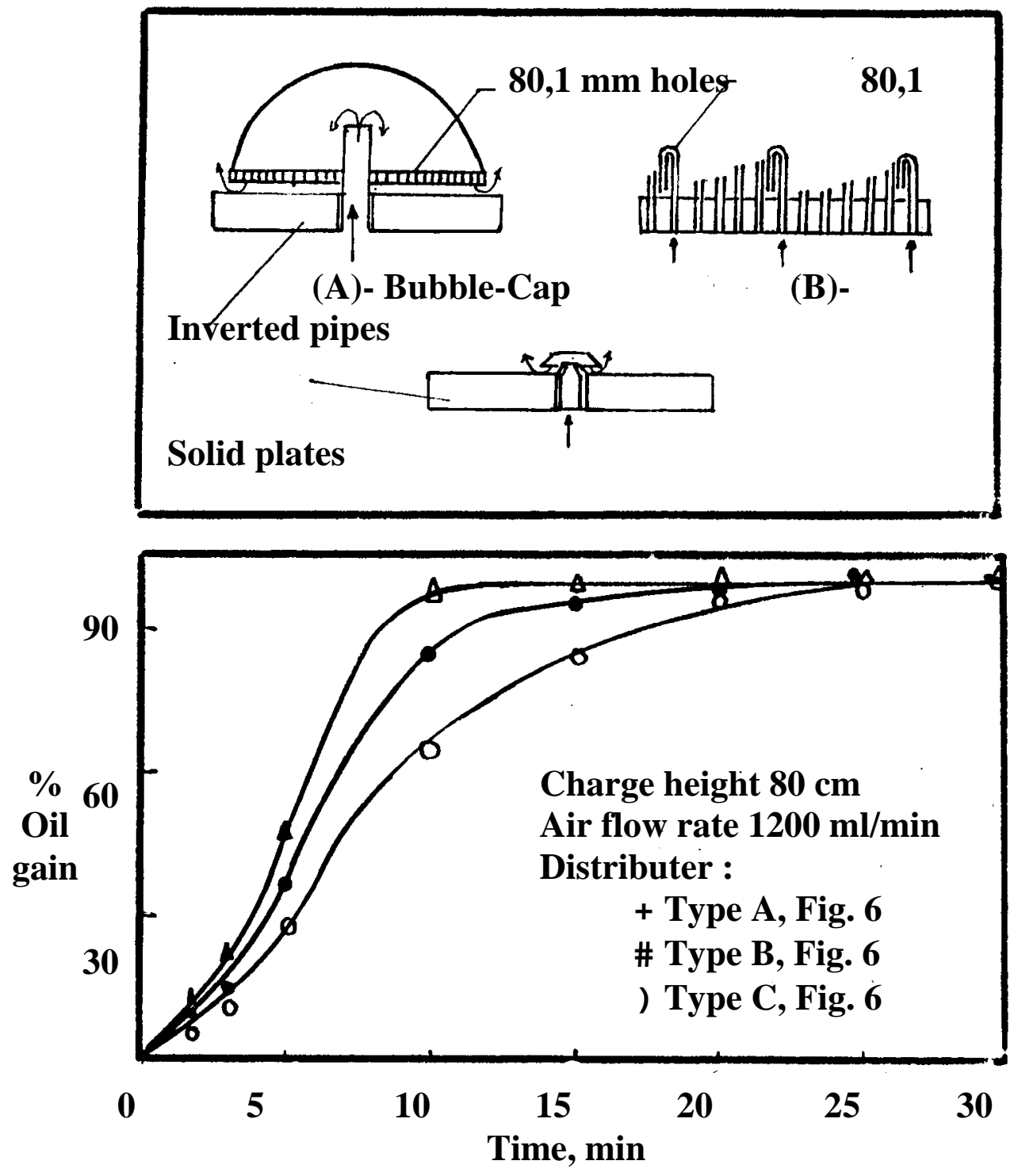

Fig. 7. Effect of Distributer Design 